\title{
INFLUENCE OF UNDISSOLVED GAS IN WORKING FLUID ON DYNAMICS OF HYDRAULIC DRIVE OF EQUIPMENT FOR OIL AND GAS WELL DEVELOPMENT
}

\author{
A. S. Lunev, A. A. Nikitin, V. G. Shram, V. I. Afanasov, \\ Yu. F. Kaizer, and A. V. Lysyannikov
}

UDC 622.323:62-82:665.612.2

\begin{abstract}
This paper reports the results of study of the influence of gas content in working fluid on the dynamics of hydraulic drive of equipment for oil and gas well development. A mathematical model of the hydraulic drive obtained in the Cauchy form is proposed. The dependence of piston speed, pressure in the piston chamber of the hydraulic cylinder, and pressure in the rod chamber of the hydraulic drive on time at 0 and $8 \%$ undissolved gas content in the fluid is established.
\end{abstract}

Keywords: oil and gas wells, hydraulic drive, undissolved gas, bulk modulus.

The compressibility of a working fluid, which is quantitatively characterized by bulk modulus, exerts influence on the dynamics of a hydraulic drive. Unsteady hydrodynamic processes occur, as a rule, much faster than thermal processes, which allows application of local adiabatic bulk modulus of a fluid for calculations of the dynamics of hydraulic drives [1].

The working fluid of a hydraulic drive is a two-phase mixture of fluid and undissolved gas (generally air). Such a mixture may form when a tank is filled and when dynamic processes occur due to different rates of dissolution of the gas in the fluid and gas is released from the fluid upon pressure drop in different sections of the working medium flow [1]. Air compressibility is much greater than fluid compressibility, so the bulk modulus of a two-phase mixture is less than the bulk modulus of a fluid, and this is much more pronounced at low pressures [2]. Undissolved air increases pliancy of the hydraulic drive and causes delay of pressure increase in the executing components of the hydraulic drive, which produces considerable effect on the operating speed of the entire control system.

The problems of dynamics of mechanisms having a hydraulic drive were elucidated/in [1-6]. The problems of dynamics of hydraulic drives were addressed more comprehensively in [1,3]. The dependence of bulk modulus of a working fluid on pressure was referred in [4] without taking account of the dependence of bulk modulus on the gas content of the working fluid.

The dependence of bulk modulus of a two-phase mixture $B_{\text {mix }}$ (fluid and undissolved gas) on pressure and gas content was obtained theoretically in $[1,2,7,8]$ :

$$
B_{\text {mix }}=-\frac{V_{\mathrm{f}}+V_{\mathrm{g}}}{V_{\mathrm{f}} / B_{\mathrm{f}}+V_{\mathrm{g}} / B_{\mathrm{g}}},
$$

where $V_{\mathrm{f}}$ - volume of fluid, $V_{\mathrm{g}}$ - volume of gas, $B_{\mathrm{f}}, B_{\mathrm{g}}-$ bulk modulus of fluid and gas, respectively.

Siberian Federal University (Sibirskii Federal'nyi Universitet), Krasnoyarsk, Russia; e-mail: Allynev@mail.ru.

Translated from Khimicheskoe i Neftegazovoe Mashinostroenie, Vol. 55, No. 12, pp. 13-14, December, 2019. 
For practical use, it is convenient to express the parameters in equation (1) through values of the parameters at atmospheric pressure $p_{0}$. The equation most suitable for practical use is given in [2]:

$$
B_{\text {mix }}=\frac{\left(1-\alpha_{\mathrm{g}}\right) \sqrt[A]{\left(B_{\mathrm{f} .0}+A p_{0}\right) /\left(B_{\mathrm{f} .0}+A p\right)}+\alpha_{\mathrm{g}}\left(p_{0} / p\right)^{1 / n}}{\frac{\left(1-\alpha_{\mathrm{g}}\right)}{B_{\mathrm{f} .0}+A p} \sqrt[A]{\left(B_{\mathrm{f} .0}+A p_{0}\right) /\left(B_{\mathrm{f} .0}+A p\right)}+\frac{\alpha_{\mathrm{g}}}{n p}\left(p_{0} / p\right)^{1 / n}},
$$

where $\alpha_{\mathrm{g}}-$ gas content in the mixture, $A-$ absolute gas absorption, $B_{\mathrm{f} .0}-$ bulk modulus of pure fluid, $p$ - pressure in the system, $\mathrm{Pa}, n=1.1-5.0$ - empirical constant.

The influence of gas content of the working fluid on the dynamics of hydraulic drive was investigated on the example of UPA-60A equipment for oil and gas well development.

For constructing the mathematical model of the hydraulic drive of the UPA-60A equipment, the following assumptions were made: the angular speed of pump shaft revolution is constant (this can be accepted if the drive motor is provided with a revolution regulator and it maintains a constant output shaft revolution frequency); the length of the hydraulic lines is relatively short, so the influence of wave processes on the dynamics of the hydraulic drive can be ignored; the length of the intake hydraulic lines (from the tank to the pumps) is short, so their hydraulic resistance can be ignored.

The mathematical model of the hydraulic drive obtained in the Cauchy form is of the following type:

$$
\frac{d y(t)}{d t}=v
$$

where $v$ - fluid flow velocity, $y$ - distance, $t-$ time;

$$
\frac{d v(t)}{d t}=\frac{1}{m_{\mathrm{red}}}\left(p_{1} S_{1}-p_{2} S_{2}-F(y)\right),
$$

where $m_{\text {red }}-$ reduced mass of the equipment, $\mathrm{kg}, p_{1}$ - pressure in the piston chamber, $\mathrm{Pa}, p_{2}-$ pressure in the rod chamber, $\mathrm{Pa}, S_{1}, S_{2}-$ cross sectional area respectively of the cylinder and rod chambers, $\mathrm{m}^{2}$;

$$
\frac{d p_{1}(t)}{d t}=\frac{B_{\text {mix }}\left(p_{1}, \alpha_{1}\right)}{S_{1} y(t)+V_{1}}\left(Q_{\mathrm{p}}-Q_{1}-Q_{\mathrm{v}}-v S_{1}\right)
$$

where $V_{1}-$ volume of the piston chamber, $\mathrm{m}^{3}, Q_{\mathrm{p}}-$ delivery of one pump, $\mathrm{m}^{3} / \mathrm{sec}, Q_{\mathrm{v}}-$ rate of fluid flow through the safety valve, $\mathrm{m}^{3}, Q_{1}$ - rate of working fluid flow with due regard for leakage, $\mathrm{m}^{3} / \mathrm{sec}$;

$$
\frac{d p_{2}(t)}{d t}=\frac{B_{\mathrm{mix}}\left(p_{2}, \alpha_{2}\right)}{V_{2}-S_{2} y}\left(v S_{2}-Q_{\mathrm{of}}\right),
$$

where $V_{2}$ - volume of the rod chamber, $\mathrm{m}^{3}, Q_{\text {of }}-$ rate of working fluid flow in overflow hydraulic line.

The results of calculations by the mathematical model (3)-(6) of the hydraulic drive (Fig. 1) illustrate the influence of air content in the working fluid on the dynamic processes in the hydraulic drive. 


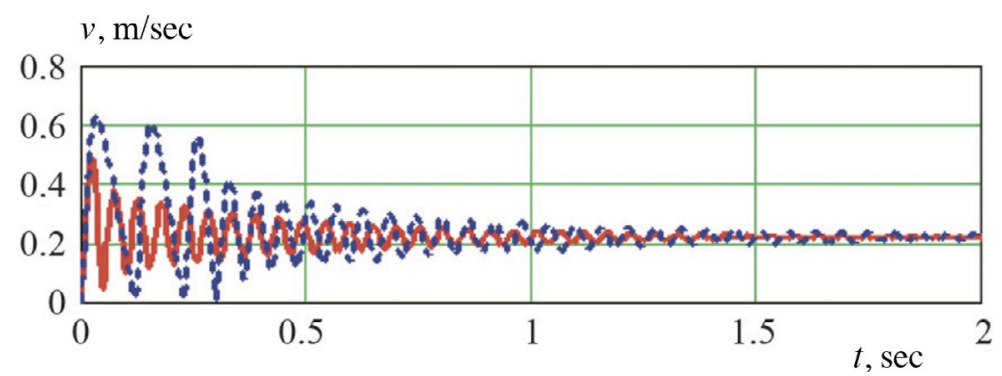

(a)

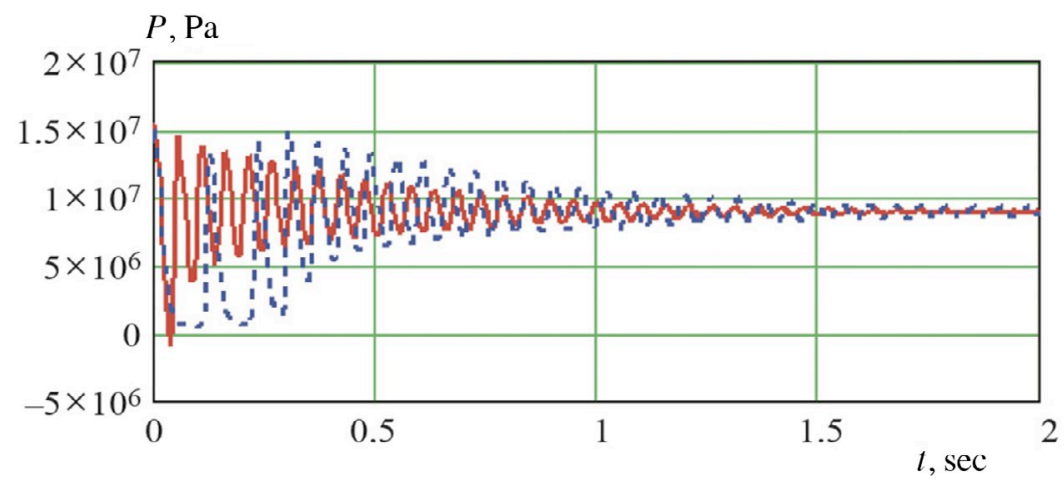

(b)

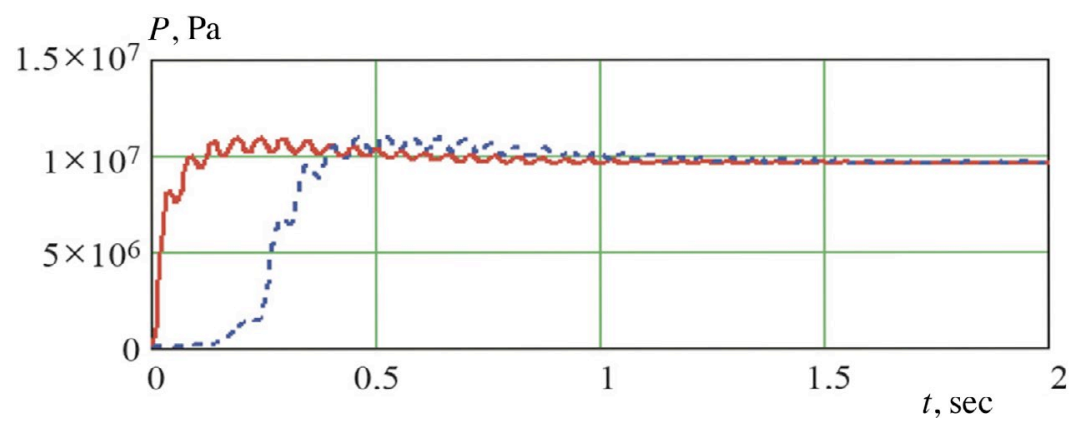

(c)

Fig. 1. Dependence of piston speed (a), pressure in the piston chamber of the hydraulic cylinder (b), and pressure in the rod chamber of the hydraulic cylinder (c) on time. Content of undissolved gas in the fluid: $--0 \% ;---8 \%$.

From the graphs in Fig. 1 it is evident that the increase of undissolved gas content in the working fluid affects the pattern of change of hydraulic drive parameters. With rise of the undissolved gas content from 0 to $8 \%$ the amplitude increases and the piston speed fluctuations decrease in the initial period of piston motion; the amplitude of pressure fluctuations in the piston chamber of the hydraulic cylinder increases (pressure overshooting does not occur because the average pressure decreases); the frequency of pressure fluctuation in the piston chamber of the hydraulic cylinder decreases and the pressure fluctuation pattern bears an inharmonic nature in the initial period of piston motion; the pressure in the rod chamber of hydraulic cylinder rises more slowly.

The influence of undissolved gas in the working fluid on the performance of the hydraulic drive is most pronounced at the initial stage of piston motion.

Application of the developed mathematical model (3)-(6) will help at the hydraulic drive designing stage investigate the influence of undissolved gas content in the working fluid on the dynamics of change in parameters of the hydraulic drive and also select the optimum values of the drive parameters. 


\section{REFERENCES}

1. D. N. Popov, Mechanics of Hydraulic and Pneumatic Drives [in Russian], Izd. MGTU im. N. E. Baumana, Moscow (2002).

2. N. F. Metlyuk and V. P. Avtushko, Dynamics of Pneumatic and Hydraulic Drives of Vehicles [in Russian], Mashinostroenie, Moscow (1980).

3. E. A. Mandrakov and A. A. Nikitin, Dynamics of Hydraulic Systems [in Russian], INFRA_M, Moscow; Sib. Feder. Univ., Krasnoyarsk (2014).

4. B. L. Korobochkin, Dynamics of Hydraulic Systems of Machine Tools [in Russian], Mashinostroenie, Moscow (1976).

5. V. N. Prokop'ev (editor), Dynamics of Hydraulic Drive [in Russian], Mashinostroenie, Moscow (1972).

6. A. A. Nikitin and E. A. Mandrakov, "Influence of undissolved gas in working fluid on dynamics of hydraulic drive of logging machine," Izv. Tomsk. Politekhn. Univ. Matemat. Tekhn. Fiz., 325, No. 2, 65-71 (2014).

7. D. N. Popov, S. S. Panaiotti, and M. V. Ryabinin, Hydromechanics [in Russian], edited by D. N. Popov, Izd. MGTU im. N. E. Baumana, Moscow (2002).

8. N. S. Gamynin, Hydraulic Drive of Control Systems [in Russian], Mashinostroenie, Moscow (1972). 